\title{
Application of BIM modeling for the organization of collective work on a construction project
}

\author{
Venera Garyaeva* \\ Moscow State University of Civil Engineering, Yaroslavskoe shosse, 26, Moscow, 129337, Russia
}

\begin{abstract}
The article discusses the issues of organizing collective work on an information model in an environment of common data using the means of ensuring interdisciplinary coordination. Working in a common data environment allows you to work in parallel on the project, which helps to accelerate the development of the project and allows you to monitor and respond quickly to changes and collisions.
\end{abstract}

\section{Introduction}

In the construction industry of Russia there is an active transition to information modeling technologies - BIM (Building Information Modeling). As is known, the emergence of new technologies and their implementation entails the need to develop appropriate regulatory acts, including the formation of a national system of BIM standards, the restructuring of the principles of the design and construction organizations, the writing of corporate regulations and other documents $[1,2]$.

Information modeling is considered not only as a powerful approach to design, which consists in creating a computer model of a building used to solve specific tasks throughout the life cycle, but also as a way of interaction between all project participants, including executors and customers. That is, BIM is a tool for organizing interdisciplinary interaction between project participants. The developed model of a building or structure using BIM technologies becomes available to any participant, which is possible thanks to the common data environment. Thus, information modeling at the moment is an opportunity to substantially simplify the work of all participants in investment and construction activities at all stages of the life cycle $[7,10]$.

\section{The problems that arise when implementing BIM}

In order to ensure correct operation in the common data environment, it is necessary to standardize the processes of production and transfer of project information, and also to implement agreed standards and methods that ensure a unified form and quality of repeated and reusable information created once.

\footnotetext{
* Corresponding author: ngaryaev@gmail.com
} 
BIM standards of the organization should include a single terminology, roles and responsibilities, levels of development, common BIM templates and platforms, common data environment, naming rules, data exchange formats, modeling technology, BIM component development, BIM model validation, and also, the plan for the implementation of the BIM project.

The need to implement a single BIM-standard is due to several factors. There are four main factors that characterize the organization's need to follow a single standard:

- the creation of the basis for the development of a system of quality checks of the BIM model,

- providing a basis for training,

- the ability to prevent repetition of errors,

- is the best way to preserve the accumulated experience.

The key provision for the development of standards is the provision of collective work on the project.

The main components in the organization of team work on the project are the common data environment, shared access to the composite model, a table of composite detail levels (LOD), common data exchange formats, messaging and control of changes in the model, and technical workflow.

\section{Approaches to problem solving}

At the moment, there are several ways to organize a common data environment: cloud storage, access through a local network, a single portal.

4 types of data are distinguished: data in the robot, data published, data shared and archive.

Data in the work is data that is used only within the group.

Published data - approved output project data, available to all project participants.

The data in the public domain is the verified project data available to all project disciplines (data for interdisciplinary coordination).

The archive acts as a means of storing all versions of the project.

To date, there is a large number of software solutions in the field of information modeling technologies $[4,5,6]$. In this paper, ArchiCAD Teamwork (BIM Server) is considered as a software tool for providing interdisciplinary coordination. The Teamwork function in ArchiCAD is designed for the work of all specialists, including architects, designers, builders, engineers, designers, etc.

The modern design process involves the participation of many specialists in the work. Therefore, the connection to one common project and the joint work with it is, to date, a demanded feature in modern software systems, which is implemented in Teamwork. For example, an architect, developing a project, can give access to his file to other specialists, who in turn can track changes in the project.

To get started with Teamwork, you need a static IP address and an open port in the router settings, as well as a BIM server installed. Work on the project is possible from any computer with any OS. The person who installs the server on their computer provides their IP address to colleagues. The project participants, in turn, enter this address and port for connection and work, as well as their own user name and password.

Access to the server is through the browser. You can view the server address and configure it, assign tasks to accounts, access to server partitions (projects, users, roles, libraries, modules), view server version information, general parameters, connection parameters, where you can add - Alternative addresses, email parameters, a module with general information (for each version of ArchiCAD there is a module). The settings allow you to install new users who plan to join the team work. For these users the name, login, 
password, e-mail are indicated. Only after that the created user can connect to the server for team work. Then the new participant is assigned a role and access control so that he can make his own adjustments and have corresponding functions.

By setting the role, each participant is assigned the right to work. For each specialist from the general list, the functions available to him are selected. That is, a certain role assigned to project participants provides a limited set of functions for changes, viewing a common project. You can also create your own roles and edit them.

The BIM server loads projects designed for collective and / or remote work. The functionality of this software allows you to edit the status of the project, delete, move, duplicate, track the activity of participants, change access to project participants, etc. So, in the images tab there is information about creating work images, which can also be edited. In the case of a new version of ArchiCAD, you can export the project image to a new server.

The library section displays the libraries that are uploaded to the server. In the work on the project, it is possible to use only those elements that have been preloaded on the server.

Work with Teamwork begins when the server settings are completed. At this stage, the process of saving files to the server is performed. A user who has access to the server must upload the project to it. The project is uploaded to the server, and then two copies of the project are obtained, i.e. one is stored on the server itself, and the other is downloaded to the folder by a local copy.

The Teamwork panel allows you to organize a workspace for project participants, track changes, exchange data, display reserved items, display user information.

Another key factor in the organization of joint work on the project is the observance of uniform data formats. The experience of the world practice recommends the use of open data standards - IFC (Industry Foundation Classes) or BCF (BIM Collaboration Format) for representing models of projected objects. IFC is a recognized international format with an open specification that does not belong to anyone, and any software developer can use it. To use it, each program has its own specific parameters. That is, IFC format is considered as the main tool for data transmission of the information model within the framework of information interaction.

An important aspect in the organization of collective work on the project are levels of development of LOD, which serve as a tool for planning the BIM project. The level of elaboration formalizes the volumes of information transmission on the project between adjacent disciplines, acting as a language of communication both between subcontractors, and between the contractor and the customer. One of the most important functions of the levels of study is the ability to determine the required composition of the model at each stage of project development.

When working on a collaborative project in a common data environment, a number of problems can arise.

In NIU MSSU within the framework of the disciplines Automation of architectural design and Information support of CAD using the tools of collective work Graphisoft a project of a residential quarter including 2 multi-apartment 9 and 15-storey residential houses was developed.

The work was carried out in parallel on the design of two residential complexes of different number of storeys. In the course of teamwork, the following problems were identified:

- the lack of common project templates, understanding of the unified settings of the project structure, the parameters of the information model, the settings for the composition of the statements and specifications. In this regard, preference was given to work in a single project file with single pre-configured and designated parameters. An alternative to this 
approach can be the development of individual project files and the collection of them in a single environment, but this process is more time-consuming.

- the need to add library elements, new line types and other objects through the project administrator to a single project library, which is an additional burden on the administrator for quality control and duplication.

As a result, after the adjacent works on the project are ready, a consolidated model for the project is being formed. The main purpose of the composite model is to support the processes of harmonizing technical solutions, identifying collisions, calculating volumes. The ready-made composite model is designed to merge adjacent sub-projects into one project and serves to identify collisions at the design stage. It is important to note that the composite model only acts as an opportunity for verification on a collision, and not as a means of correcting them.

Large Western companies have already tried using BIM-technologies when working with serious projects. Their successful experience is proof that the introduction of BIMtechnologies in Russia is a huge step forward.

An example of a successful and serious project, built on the principle of teamwork, can be the development of a project of a large shopping and entertainment center "Respublika" in Kiev using ArchiCAD. The project was developed in the environment of ArchiCAD Teamwork, which significantly accelerated the work on the project. According to the statement of one of the project developers, thanks to teamwork, the architects were able to respond much more quickly to changes and collisions that come from developers of related disciplines. Thus, when designing objects, especially large objects, the role of teamwork comes first.

\section{Conclusions}

Thanks to the technologies of information modeling, project participants have the opportunity to interact with each other in the development of the project, which greatly simplifies and speeds up the work. Information modeling technologies are designed to provide new collaborative processes through the organization of common access to the project. Participants are made available: visual 3D visualization, interdisciplinary coordination, parallel work, 3D communications between participants, tracking and making changes, assessing the current scope of work. It is also worth noting that today BIM acts as a means of control over the project on behalf of the customer himself.

\section{References}

1. Adamtsevich A., Ginzburg A., Shilova L., Shilov L. Implementation of BIM technologies in the Russian construction industry according to international experience / Journal of Applied Engineering Science, 14 (4), p. 457-460 (2016)

2. Afanasyev A., Ginzburg A., Kozhevnikova S., Stepanov V. Organization of specific works based on the information tracking system / Materials of the 19th International Scientific Conference "Energy Management of Urban Transport and Transport Facilities EMMFT 2017". Khabarovsk, Russia April 10-13, 2017. Advances in the field of intelligent systems and calculations, v. 692. Springer, Cham. https://doi.org/10.1007/978-3-319-70987-1_126.

3. Bolotova A., Ginzburg A., Dolganov A., Vedyakov I., Weinstein M. Organizational and technological reliability of monolithic construction / Materials of the 19th International Scientific Conference "Energy Management of Urban Transport and Transport Facilities EMMFT 2017". Khabarovsk, Russia April 10-13, 2017. Advances in the field of 
intelligent systems and calculations, v. 692. Springer, Cham. https://doi.org/10.1007/978-3-319-70987-1_124.

4. Garyaev N A Development and analysis of the hotel complex information model. The MATEC 2016 Conference Network. C. 06007.

5. Garyaev N A Geographically distributed educational network. Calculation in the works of civil and construction engineering 2014 International Conference. 2014. S. 15781585 .

6. Garyaev P N Computer zoning and urban planning. Calculation in the works of civil and construction engineering 2014 International Conference. 2014. P. 1618-1625.

7. Garyaeva V V, Garyaev N A Comprehensive assessment of the technical condition of housing projects based on computer technology. Calculation in the works of civil and construction engineering 2014 International Conference. 2014. P. 1336-1343.

8. Kagan P. Engineering communication networks - the use of standards for the presentation of information in the design, construction and operation, Engineering 25th., "25th Polish-Russian-Slovak Seminar-Theoretical Foundation for Civil Engineering", pp. 261-265. (2016)

9. Kagan P B, Barabanova T A, Formal Language of the Description of Technological Processes in Construction, Calculation in Civil and Building Engineering - pp. 22322237 (2014)

10. Ryzhkov A., Ginzburg A., Accounting for "pure" risks at an early stage of investment in construction projects using energy-efficient technologies / Applied Mechanics and Materials. 672-674 (2014), Trans Tech Publications, Switzerland, 2014, -pp. 2221-2224 